\section{EXFOLIATIVE DERMATITIS}

\section{OCCURRING DURING ARSENICAL TREATMENT.}

(With a Note on Toxic Jaundice.)

BY E. G. FFRENCH, M.D., F.R.C.S. EdIN., MAJOR, R.A.M.C.; LATE ACTING LIEUTENANT-COLONEL COMMANDING 5IST GENERAL HOSPITAL, FRANCE.

DURING nearly ten year's' experience with arsenical preparations in various. parts of the world many thousands of cases of syphilis have come under my supervision, and it is my opinion that severe cases of exfoliative dermatitis and toxic jaundice occur only in a very small fraction. From time to time cases of erythema occurred after one or more injections, but this condition soon disappeared; the erythema has the appearance of a scarlatiniform or morbilliform rash, and has frequently been mistaken by inexperienced medical officers for scarlet fever. In some cases it is accompanied by high pyrexiä, 104 or $105^{\circ}$, but more often than not it is comparatively mild. It may also be mistaken for German measles, and acute cases become severely ill. Desquamation follows these cases.

The erythematous condition in mild cases may be limited to a part of the body for example, the neck or chest and abdomen. In severe cases it spreads over the whole of the body, and if it then develops into exfoliative dermatitis a very severe condition has come about and the patient's life is in danger. Both these conditions come on at varying periods during the course of treatment. Some patients will develop severe dermatitis after the second injection of $0^{-6} \mathrm{~g}$. N.A.B.; others later in the course. Sometimes it makes its appearance immediately after the course of seren weekly injections of $0.6 \mathrm{~g}$. N.A.B. I have never seen it develop later than a month after completion of treatment.

During several years in India and London I saw only four cases of severe exfoliative, but during service in France I had some 20 cases under my supervision. I feel-convinced that the majority of these cases were due to exposure to cold: The conditions could not be as comfortable as in hospitals at home and the patients were less protected. Practically all the cases occurred during the winter months, and, morever, the fact that only two officers out of close on 2000 under treatment for syphilis developed severe dermatitis was significant. The officers had more comfortable accommodation and were able to go to a warm bed immediately after the injection and remain there for 24 hours. Although warm spring beds were provided for the soldiers for the first 24 hours after the injection, it was most difficult to keep them there owing to the large numbers undergoing treatment.

\section{The Clinical Picture.}

In severe exfoliative dermatitis the whole body is usually covered with a scarlatiniform rash, but somewhat darker in colour. This sometimes becomes confluent over parts of the body. Not infrequently small blebs make their appearance behind the ears and on the neck. Pustules and blebs form all over the body, and after these have ruptured crusting and scaling develop. Itching is very troublesome and becomes a burden to the patient. There is always a great deal of swelling of the face, involving the lips, nose, eyelids, ears, and cheeks. The conjunctivx become very inflamed, lachrymation and photophobia being particularly trouble some. A weeping eczematous condition is nearly always present in some parts of the body, the ears, lips, axill pubis, and scrotum being frequently affected in this way. The eyelids are very often so swollen that the patient is unable to see. The skin takes on a deep reddish-brown tint and there is a great deal of exfoliation of the epidermis subsequently. The weeping eczema and the presence of large pustules in various parts of the body, especially in the axillæ and groin, are two most distressing complications. When the acute stage is passed the skin is deeply pigmented and is harsh, thin, and atrophic. The scalp becomes swollen and eczematous, and settles down after a time with almost complete loss of hair, which grows again in the course of a few months. The eyelashes are frequently shed, but grow again. The soles and palms develop thick epidermic plates (hyperkeratosis), which are completely shed during convalescence; the nails also become affected. In a few cases there is high fever and healache, with diaxrhoa, retching, and vomiting of bile-stained fluid. The patient usually looks and is very ill; the fauces are congested and the tongue is dry and brown. Owing to the loss of sleep due to the irritation of the skin condition and the toxic state of the patient his health becomes very much impaired, and he goes down hill rapidly. (Edema of the lungs and bronchopneumonia often complicate these cases and cause the fatalities.

In some of the severe cases the eruption is hæmorrhagic in several parts of the body. There is always marked general adenitis, and the glands, especially those of the axillæ, get very large, soft, and tender; not infrequently they break down. The urine nearly always contains a small amount of albumin. During the process of desquamation

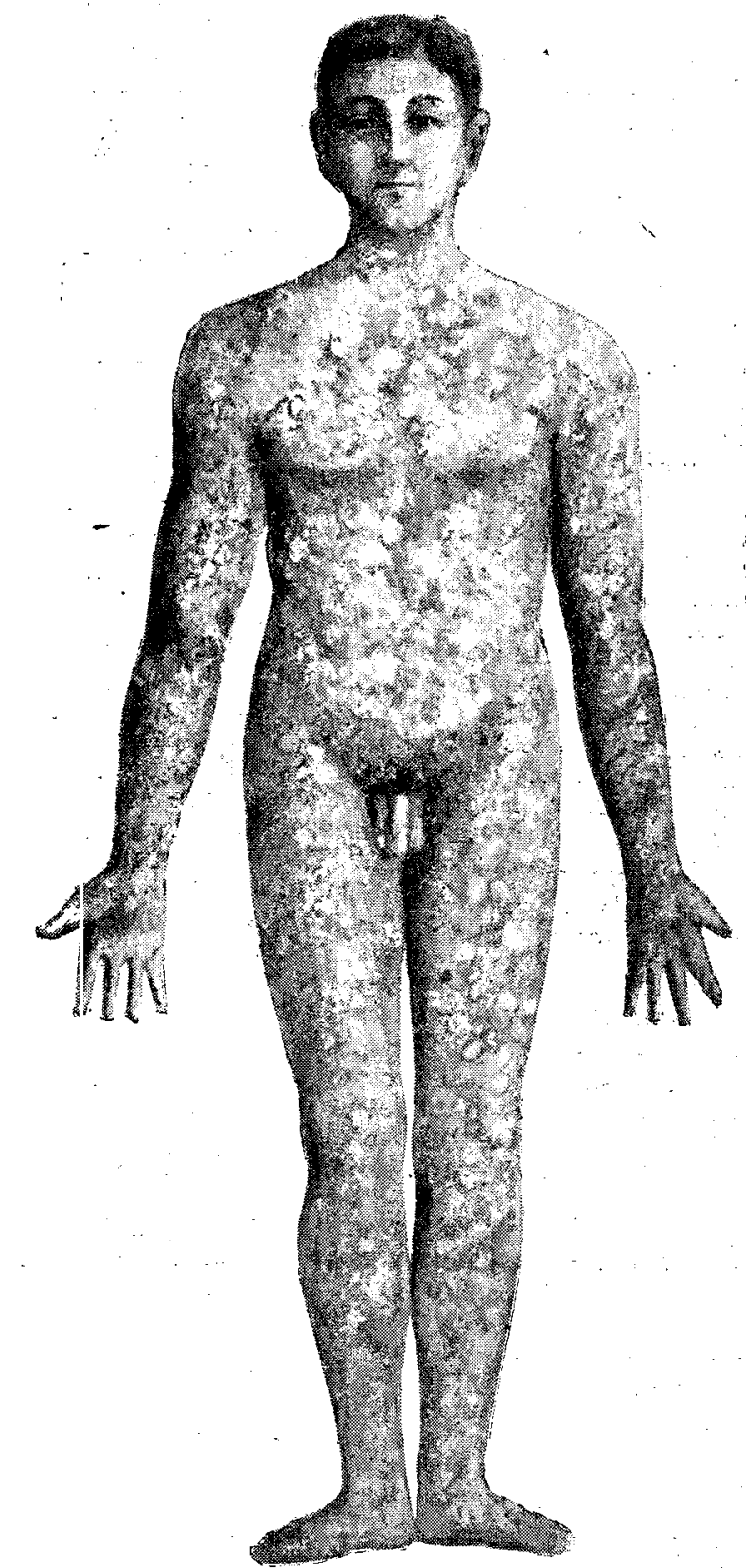

Patient suffering from exfoliative dermatitis. (Reproduced from a coloured drawing.)

the patient's bed is practically covered with flakes and large scales; after the desquamation the skin is smooth, having a somewhat glazed pinkish look. The convalescence to com plete recovery is slow, but the patient often makes rapid progress after the acute illness. As soon as the symptoms have subsided his appetite, which is very poor, improves markedly, and he begins to take an interest in himself. The depression, which is a characteristic feature, disappears and his general health steadily improves. After the desquamation is complete the patient is very much altered in appearance, and it is doubtful if his best friend would recognise him at first sight. However, after three or four months he regains nearly all his characteristics and looks like a normal individual again.

\section{Prognosis.}

The prognosis is favourable when appropriate treatment is applied as soon as the condition is diagnosed. Iung com. plications not infrequently develop in spite of all precau tions, and in these cases the prognosis is bad. It is $m$ experience that the more severe is the skin affection the greater the internal complications, which put the patient in great peril of his life. Of the three cases who died with 
lung complications all had the most extensive and severe dermatitis imaginable. The mild cases responded to intramine readily, and I have never seen any appreciable internal complications in any of them.

\section{Treatment.}

In cases where the eruption is one of simple erythemalotio calamine, calamine cream, and bran baths. Intramine I consider the best remedy, $2.5 \mathrm{c.cm}$. of intramine being given intramuscularly in the buttock in the same manner as an intramuscular injection of mercury. This is repeated every fifth day until the disappearance of the erythema in simple cases or the exfoliation in severe cases. In mild cases two doses will be sufficient, but in severe cases five to ten doses are often required. I commenced the use of intramine in these cases in 1917 and have used it in every case since then. At first Mr. J. E. R. McDonagh, who was then working in the same hospital and who introduced the drug to the profession, advised the full dose of $5 \mathrm{c.cm}$. of the original preparation, but we found that this produced too much reaction and decided to make the dose $2.5 \mathrm{c} . \mathrm{cm}$. After a little experience it was found that this dose produced little or no reaction, and could be given at intervals of five days without inconvenience to the patient. After a time Mr. McDonagh put up his preparation in two separate tubes, which had to be mixed before injection. For convenience I have been using $3 \mathrm{c.cm}$. of the mixture for each dose. 'The drug acted quickly, producing most satisfactory results. In some cases an appreciable amount of discomfort at the site of injection for 24 or 48 hours was noticed by the patient, and in nearly every case the temperature rose $2^{\circ}$ and fell on the following morning, and did not rise again until the next dose was given. It is thought that dermatitis is caused by over-oxidation of the tissues of the body by arsenic, and as intramine acts as a reducing agent in the body it produces good and speedy results. In those cases of generalised erythema with hyperpyrexia $\left(105^{\circ}\right)$ and headache, venesection has proved most satisfactory and has aborted the severe symptoms. From 10 to 15 ounces of blood should be withdrawn, but, unfortunately, venesection does not prevent all cases from developing severe symptoms. However, it should always be carried out as early as possible in these acute cases.

When the stage of pustular eruption develops ichthyol ointment 10 per cent., or lead and zinc paste, are very valuable applications; for the weeping eczematous condition calamine lotion, zinc oxide and starch lotion, and zinc oxide ointment, at a later period; calamine powder is also useful. For the conjunctivitis two or three drops of argyrol, 25 per cent., dropped into the eyes morning and evening effect a speedy cure. Boric lotion should be used after the argyrol. Before the introduction of intramine the above local remedies were the chief ones in use for treating cases of exfoliative dermatitis and recovery took many months. Nowadays, with the use of intramine, an amino-sulphur compound, they recover in one quarter of the time.

The diet should consist of milk and soda, plenty of barley water, milk puddings of all kinds. Lime water should be added to the milk if there is diarrhoea or digestive disturbance. Meat, meat extracts, and eggs are contra-indicated. Tonics should be prescribed. Further treatment with arsenic is commenced during the convalescent period; the patient by this time has desquamated, is feeling fairly well, and is able to walk about the ward. Only half the original dose is administered weekly-namely, $0 \cdot 3 \mathrm{~g}$. N.A.B. The patients invariably do well afterwards. I have used all the arsenic preparations at different times, but with the exception of four all the cases occurred in France, where N.A.B. was the preparation in use.

Post-mortem Findings of the Three Fatal Cases of Exfoliative Dermatitis.

CASE 1.-Brain: A little thickening of the pia at the vertexotherwise normai. Lungs: Broneho-pneumonia right lower lobe, otherwise cedema; some small amount of pus in small tubes. Heart: $8 \frac{1}{2}$ oz., small, firm. No V.D.H. Kidneys: $8 \frac{1}{2}$ oz., large,

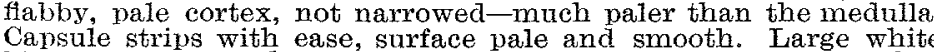

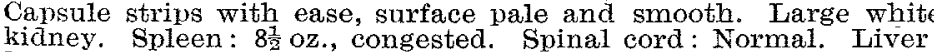
$52 \mathrm{oz}$., pale, fatty. No subserous hæmorrhages. Marked exfolia tive dermatitis.

CAsE 2-Skin: Petechiæ. Lungs: Both lungs cedematous. No

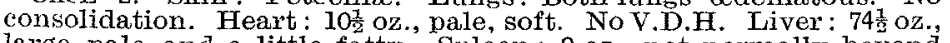
large, pale, and a little fatty. Spleen : 9 oz., not normally beyond Cortex strips maturally surface smooth. No subserous hpeted rhages. Marked exfoliative dermatitis. CASE 3.-Skin: Petechiæ. Lungs: Several infarcts in each with
a little surrounding broncho-pneumonia and overlying pleurisy. a little surrounding broncho-pneumonia and overlying pleurisy.
No fluid in pleura. Subpleural, petechiæ. Heart: $9 \frac{1}{2}$ oz., dilated, pale, very soft. No V.D.H. Liver: 59 oz., somewhat fatty. Spleen : 7 pa., not abnormal. Kidneys: 69 and $6 \frac{1}{2}$ oz., pale, not swollen. Capsule strips naturally. Marked exfoliative dermatitis. There was severe inflammation of the whole of the alimentary canal which prevented easy swallowing and digestion; this patient had to be fed per rectum a few days before his death. He was admitted suffering from severe secondary syphilis, with involvement of the iris. He did remarkably well until a few days after the completion of his course when dermatitis developed. In spite of early treatment with intramine he got rapidly worse.
The dermatitis in all three cases occurred within a month cf completion of a course of moderate dosesviz., 0.6 g. N.A.B. Cases 1 and 2 were readmitted suffering from lung complications.

\section{TOXIC JAUNDICE.}

I am of opinion that there are certainly two types of jaundice occurring during the early stages of syphilis.

First type.-The jaundice not infrequently appears before treatment with arsenic. There are some medical officers who persistently attribute every case of jaundice in syphilitics to arsenic compounds. I have seen those medical officers enter a ward containing special cases and. ask as they go up to the bedside of the patient with jaundice, How many doses of "606" has this patient had? When told that the patient has not had any arsenic preparations, being only a recent arrival, they look astounded. Having trea ted venereal diseases for over 20 years I have noticed many cases of mild jaundice in patients suffering from syphilis. We always used to consider that syphilis caused the jaundice, there being no specific arsenical preparations in those days to put the blame on. Several cases have been noticed after the first two or three injections of arsenic. This comparatively mild jaundice is, no doubt, due to a widespread fatty degeneration of the liver cells caused by toxins of the Treponema pallidum.

Second type.-What is really arsenical jaundice comes on towards the end of the course of seven weekly injections of $0.6 \mathrm{~g}$. N.A.B. In all probability it is due to the syphilitic degeneration of liver cells as well as to the toxic action of arsenic. The jaundice is intense, the patients become seriously ill, and the disease is very liable to end fatally unless prompt treatment is applied. This type of jaundice is the result of an intense catarrh of the minute bile-ducts. The colour of the skin and conjunctivæ is of an intensely deep yellow-urine yellowish brown or dark brown, stools very pale. Fifteen cases of this toxic type came under my supervision from time to time, two of whom ended fatally.

\section{Treatment.}

In both the mild and severe cases I consider that intramine is the best remedy we have at our disposal. It is given intramuscularly into the buttock and in doses of $3 \mathrm{ccm}$. at intervals of five days. In mild cases two doses are sufficient, but in the more severe cases as many as ten injections have been given. I believe I am right in saying that intramine was first used in treating jaundice in 1917 at No. 51 General Hospital. Mr. McDonagh and I decided to employ it in all crses suffering from jaundice. Arsenical preparations in half the usual dose were given to the patient as soon as the jaundice cleared, and were continued until the full amount of the course was completed. Other remedies, such as sodium sulphate, calomel, and bismuth and soda, were also administered. The intramine in these cases also acted as a reducing agent.

Post-mortem Findings of Two Cases of Toxic Jaundice.

CASE 1.-Brain: A little excess of cerebro-spinal fluid and a ossification. Lungs: Subpleural petechiæ and hæmorrhages, a few interstitial hæmorrhages, cedema, no consolidation. Heart: $7 \mathrm{oz}$, small, subpericardial hæmorrhages. Muscle not soft. No V.D.H. Liver: 25 oz., very small, brownish with many slightly raised greenish areas; these are found on section to blend and occupy large areas of the total liver. Spleen: $7 \frac{1}{2}$ oz, large, soft, and pale. Structure not recognisable. Kidneys: $4 \frac{1}{2}$ and 5 oz., yeliow and swollen cortex. Kidney as a whole is small. Capsule
strips naturally. Stomach: Submucous hæmorrhages, also hemorrhages in omentrm and behind peritoneum of posterior abdominal wall. A subserous hæmorrhage in the ileum. Sir John Rose Bradford, the consulting physician of the area, witnessed the post-mortem examination, and expressed the opinion that the condition of the liver was not true yellow atrophy. The above was a case of a congenital sypbilitic showing bossing of
the skull and saddle-back nose, who developed a typical syphilitio the skull and saddle-back nose, who developed a typieal syphilitio was only given $045 \mathrm{~g}$. doses of N.A.B. and developed his jaundice was only given $045 \mathrm{~g}$. doses of N.A.B. and developed his jaundice
after the fourth injection. Intramine was given, but had no appreciable effect.

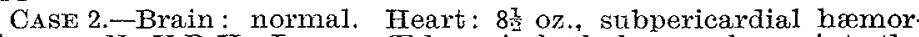
rhages. No V.D.H. Lungs: CEdema in both, hæmorrbages into the subpleura. Liver: 27 oz., very small, brownish in appearance, with greenish areas similar to first case. Spleen: 7 oz., somewhat pale and sort, strueture becoming unrecognisable. Kidneys : 5 and $5 \frac{1}{2} \mathrm{oz}$. cortex swollen and pale, capsule not adherent. Stomach: Hromor mucous hemorrhases. Jaundice appeared after the sixth injection of $0.6 \mathrm{~g}$. N.A.B.

The post-mortem examinations were carried out by $\mathrm{Dr}$. T. H. G. Shore, then pathologist, Etaples Area, France.

INFLUENZA OUTBREAK AT SrmLA.-With the sudden advent of .warmer weather, infuenza, which has been smouldering for some time past, has now broken out somewhat acutely. The Indian quarters are most affected. Influenza has appeared also in the neighbouring states, where the mortality rate is considerable. The local authorities have issued a notice inviting attention to methods of prophylaxis. 